\title{
Utilização do resíduo do corte do mármore e granito como adição no concreto
}

O concreto na engenharia civil é de extrema importância pela sua versatilidade e ótima resistência à compressão aliado a um ótimo custo benefício. No entanto apesar de todas estas qualidades ainda há espaço para desenvolvimento deste material na engenharia, e junto disso há a necessidade de uma melhor destinação de resíduos. Os resíduos gerados pelo corte de mármore e granito na grande maioria dos casos não possui uma eliminação de forma adequada. Desse modo, a adição destes elementos ao concreto a fim de melhorar sua trabalhabilidade bem como sua resistência à compressão torna-se bastante viável. O presente trabalho busca realizar a adição do resíduo do corte do mármore e granito em composições de 5, 10 e $15 \%$ em relação à massa do cimento na confecção de corpos de prova de $10 \times 20 \mathrm{~cm}$. Os corpos de prova são submetidos aos ensaios de compressão axial e de trabalhabilidade para análise dos resultados com adição em relação a um concreto convencional de referência. Com os resultados obtidos foi possível verificar que o concreto com a composição de $5 \%$ obteve uma resistência maior do que os demais, e foi constatado um aumento da fluidez proporcional ao aumento do teor de finos dentre os ensaiados.

Palavras-chave: Concreto; Granito; Mármore.

\section{Use of marble and granite cut residue as addition to concrete}

Concrete in civil engineering is of utmost importance for its versatility and optimum compressive strength coupled with a great cost benefit. However, despite al these qualities there is stillroom for development of this material in engineering, and together there is a need for better disposal of waste. The waste generated by cutting marble and granite in the vast majority of cases is not disposed of properly. Thus, the addition of these elements to the concrete in order to improve its workability as well as its compressive strength becomes quite feasible. The present work seeks to perform the addition of marble and granite-cutting residue in compositions of 5,10 and $15 \%$ in relation to the cement mass in the manufacture of $10 \times 20 \mathrm{~cm}$ specimens. The specimens are submitted to axial compression and workability tests to analyze the results with addition in relation to a conventional reference concrete. With the obtained results it was possible to verify that the concrete with the composition of $5 \%$ obtained a greater resistance than the others, and it was verified an increase of the fluidity proportional to the increase of the fines content among the tested ones.

Keywords: Concrete; Granite; Marble.

Reviewed anonymously in the process of blind peer

Matheus Oliveira Sena (iD)

Unidade de Ensino Superior Dom Bosco, Brasil http://lattes.cnpq.br/6139273453591965 http://orcid.org/0000-0001-5146-2748 matheus osena@hotmail.com

Danielle Cristina dos Santos Lisboa (10) Unidade de Ensino Superior Dom Bosco, Brasil http://lattes.cnpq.br/3350912872257730

http://orcid.org/0000-0001-8707-2442 daniellecristinaeng@gmail.com

Lucas Nadler Rocha (iD

Unidade de Ensino Superior Dom Bosco, Brasil http://lattes.cnpq.br/8693441362635767 http://orcid.org/0000-0003-1424-2054 lucasnadlerrocha@hotmail.com
Lucas dos Santos Zenkner (iD

Unidade de Ensino Superior Dom Bosco, Brasil http://lattes.cnpq.br/7556110688320963 http://orcid.org/0000-0002-9408-3833 lucaszenkner1@hotmail.com

Fabrício da Silva Cordeiro (iD

Unidade de Ensino Superior Dom Bosco, Brasil http://lattes.cnpq.br/2012705875313635

http://orcid.org/0000-0002-5723-1788

fabricio.cordeiro@undb.edu.br

Renata Medeiros Lobo Muller

Unidade de Ensino Superior Dom Bosco, Brasil http://lattes.cnpq.br/2366742124450336

http://orcid.org/0000-0001-5202-837X

renata.muller@undb.edu.br
Claudemir Gomes Santana (ii

Unidade de Ensino Superior Dom Bosco, Brasi http://lattes.cnpq.br/000546442604107 http://orcid.org/0000-0003-0917-2936 csantana0405@gmail.com

\section{Referencing this:}

SENA, M. O.; LISBOA, D. C. S.; ROCHA, L. N.; ZENKNER, L. S.; CORDEIRO, F. S.; MULLER, R. M. L.; SANTANA, C. G.. Utilização do resíduo do corte do mármore e granito como adição no concreto. Engineering Sciences, v.8, n.1, p.27-37, 2020. DOI:

http://doi.org/10.6008/CBPC2318-3055.2020.001.0004 


\section{INTRODUÇÃO}

O mercado de pedras ornamentais é bastante consolidado no Brasil, principalmente relacionado à construção civil. Esse tipo de material é bastante utilizado para revestimentos nas construções. No entanto, o processo de beneficiamento dessas rochas acaba por gerar grande volume de resíduos. Essa é uma situação que merece atenção, pois grande parte desses resíduos é despejada no meio ambiente sem qualquer tipo de controle. No país são geradas 165000 toneladas de pó de granito originado desse processamento (GONÇAVES, 2000).

O beneficiamento de rochas ornamentais é feito a partir do corte e serragem dos blocos para fazer chapas por meio de aparelhos conhecidos como teares (GONÇALVES, 2000). O resíduo do processamento das rochas resulta em uma 'lama' que simplesmente é retirada dos tanques e é despejada na maioria das vezes em locais impróprios (PEDROSO et al., 2017).

O mármore e o granito representam a grande maioria do número rochas ornamentais utilizadas na construção civil (OLIVEIRA et al., 2011). Sendo assim, trata-se de um material viável para ser reutilizado e minimizar essa problemática. Isso se dá não somente pela grande disponibilidade de material, mas o resíduo do corte do mármore e granito apresenta características benéficas e viáveis para sua utilização na composição de concreto e argamassas devido a sua composição química e grande quantidade de finos (PEDROSO et al., 2017).

A utilização de adições minerais no concreto tem crescido em diversos países e apresentado resultados satisfatórios e, por vezes, melhorando algumas características do concreto além de colaborar com a questão ambiental (BARROS, 2008). Sendo assim, o foco deste trabalho é avaliar o comportamento do concreto com adição do resíduo do corte do mármore e do granito. Para tal avaliação serão realizados ensaios para determinar a resistência à compressão e analisar a trabalhabilidade e coesão do concreto com adição. Além disso, serão estudadas as propriedades do concreto para que seja possível analisar o seu comportamento.

\section{REVISÃO TÉORICA}

\section{Concreto com adição de pó de mármore e granito}

Um dos materiais mais utilizados na construção civil é o concreto. Não somente na engenharia civil, mas se trata de um dos materiais mais utilizados no mundo, sendo menos utilizado somente do que água (GARCIA et al., 2014). A sua composição é constituída a princípio por aglomerante, agregado graúdo, agregado miúdo e água. A pasta é formada pela combinação de aglomerante e água, posteriormente, unindo esse material com o agregado miúdo se tem a argamassa, e por fim, com a mistura com o agregado graúdo, como a brita, por exemplo, tem-se o concreto simples (FUSCO, 2012).

De acordo com Garcia et al. (2014), o concreto pode ser denominado como um compósito cerâmicocerâmico, ou então compósito cerâmico-metal quando se trata de concreto armado. O mesmo autor cita que com a mistura dos elementos, acontecem reações químicas entre o aglomerante e a água, o que faz com que 
a mistura endureça e ganhe propriedades como grande resistência mecânica à compressão, que é a principal característica do concreto. No entanto, no que diz a respeito à tração essa resistência não é tão considerável, geralmente sendo menor que um décimo da resistência à compressão. Desse modo, por vezes é necessária a combinação com outros materiais, como é o caso do aço, que assume o papel da resistência à tração, formando assim o concreto armado (FUSCO, 2012).

\section{Granito}

De acordo com Bauer (2008) granito é definido como "Rocha plutônica ácida (75\% de sílica), granular macroscópica; cristais de 1 a 5 mm, ou maiores de cor cinza". Já Pinheiro et al. (2016), afirma que granito tem um conceito que abrange um considerável grupo de rochas que possuem em geral quartzo e feldspato em sua composição. Trata-se de um elemento que possui aspectos como alta resistência à compressão, e pouca porosidade.

\section{Mármore}

Pinheiro et al. (2016) assina-la mármores "englobam os calcários, os dolomitos de origem sedimentar e seus correspondentes metamórficos, os mármores propriamente ditos... o travertino é oriundo de rochas calcárias de origem sedimentar ricas em carbonato de cálcio". Alencar (2013) afirma define esse material como toda rocha carbonática cuja qual é possível ser polida e lustrada.

\section{Resíduo do corte do mármore granito}

As rochas ornamentais (granito, mármore, etc.) são usadas em marmorarias para diversas finalidades bem comuns nas construções como: pias, soleiras, pavimentação, revestimento, entre outros... Essas rochas passam por diversos processos para serem utilizadas: "O beneficiamento dessas rochas compreende as etapas de desdobramento, polimento e corte" (PEREIRA, 2016). De acordo com Gonçalves (2000) em alguns locais o resíduo passa por uma filtragem para reaproveitar a água. Esses procedimentos produzem poeira e lama com o restante do material que por diversas vezes não possui uma destinação correta.

Desse modo, é possível perceber a dificuldade do gerenciamento desse material, um descaso com o seu armazenamento e descarte. Além disso, o mesmo pode ocasionar em problemas graves de saúde para as pessoas que realizam essa atividade. Trata-se de uma grande quantidade de resíduo em que boa parte é simplesmente desperdiçada e caso seja descartado de maneira inapropriada pode ocasionar em danos ao meio ambiente e a população. Sendo assim, é visto que se trata de um composto que pode possuir bom proveito para a construção civil caso seja devidamente aproveitado. Além disso, é possível observar que esse material possui características viáveis para a sua utilização no concreto.

\section{METODOLOGIA}

Primeiramente, para a execução deste trabalho, foi realizada a pesquisa com base em estudos bibliográficos para obter as informações necessárias para o desenvolvimento da fundamentação teórica. 
Posteriormente, também foram utilizadas normas técnicas como base para a realização dos ensaios técnicos efetuados em laboratório.

Todos dos ensaios foram realizados no laboratório de solos e concreto da instituição de ensino UNDB, com exceção do ensaio de massa específica da areia com tubo de Chapman, que foi realizado no laboratório de materiais do IFMA - Instituto Federal do Maranhão. Todos os procedimentos, como já foram citados, foram executados de acordo com a normatização vigente.

Para a realização do estudo sobre o concreto com adição do resíduo do corte do mármore e granito é necessário aplicar um traço de referência de concreto convencional para que, posteriormente seja realizado o comparativo entre as duas composições: com e sem adição. Dessa forma, é possível analisar os reais proveitos ou detrimentos para o concreto devido à adição. Para a elaboração do traço de concreto é preciso previamente estudar os materiais que farão parte da sua composição. Sendo assim, essa parte da pesquisa é nomeada como caracterização dos materiais. Os materiais utilizados na composição são areia média, brita 01 e cimento CP - II E 40, além do pó de mármore e granito.

\section{Resíduo do Corte do Mármore e Granito}

O resíduo do corte do mármore e granito foi coletado do tanque de uma das máquinas que realizam o corte em uma marmoraria de São Luís - Maranhão. A máquina utiliza água junto à lâmina para realizar o corte das peças de mármore e granito, o que resulta em resíduo em forma de 'lama'. O material foi coletado e levado ao laboratório de engenharias da UNDB - Unidade de Ensino Superior Dom Bosco.

\section{Caracterização dos materiais}

\section{Teor de Umidade}

O teor de umidade é um aspecto importante para o estudo das características dos materiais. Para mensurar tal característica utilizou-se amostras de cada agregado miúdo separadamente. As amostras foram coletadas nas condições naturais dos materiais, então foram pesadas, selecionando-se $2 \mathrm{Kg}$ de areia média e $3 \mathrm{Kg}$ do resíduo do corte do mármore e do granito. As matérias são levadas à estufa, onde passam o período de $24 \mathrm{~h}$ para retirar a umidade. Encontrado o peso dos materiais secos é então calculado o teor de umidade de cada.

\section{Granulometria}

Os procedimentos para realização desse ensaio têm base na NBR NM 248:2003 (Agregados Determinação da composição granulométrica). Os materiais, separadamente, são levados novamente à estufa e, posteriormente passam pelo ensaio de agitação de peneiras para descobrir as respectivas granulometrias que são necessárias para a determinação do traço do concreto.

\section{Massa Unitária}

Outro fator importante para elaborar o traço do concreto é a massa unitária. De acordo com a 
NBR NM 45:2006 (Agregados - Determinação da massa unitária e volume de vazios) o conceito de massa unitária é a "relação entre a massa do agregado lançado no recipiente... e o volume do recipiente" O ensaio é realizado com base nesta mesma norma, sendo executado com cada agregado (graúdo e miúdo) separadamente. Os materiais são pesados e levados à estufa e são mantidos no equipamento pelo período de 24 horas para retirar a umidade. É selecionado um recipiente que será utilizado para calcular a massa dos materiais em determinado volume. Para isso, o volume do recipiente é calculado por meio do seu preenchimento com água que em função da sua densidade fornece o volume. Em seguida os materiais são introduzidos no recipiente onde passam por procedimentos seguindo a norma NBR NM 45:2006(Agregados - Determinação da massa unitária e volume de vazios) para encontrar os respectivos valores de massa unitária.

\section{Massa Específica}

Para obter a massa específica do agregado graúdo utilizou-se a norma NBR NM 53:2009, primeiramente o agregado graúdo é lavado, em seguida, pesado e colocado na estufa à temperatura de 105 C durante o período de 24 horas. Após esse processo, a amostra é pesada novamente. Em seguida o agregado é submerso em água pelo período de $24 \mathrm{~h}$ em um cesto de arame de abertura inferior a 3,35 $\mathrm{mm}$. Ao término desse período a amostra é retirada da água e secada com pano até retirar a água da superfície do agregado e então é pesada novamente para obter o peso da amostra saturada com superfície seca.

Então é realizada a pesagem hidrostática para executar esse ensaio foi necessário realizar uma simulação de balança hidrostática, portanto a balança comum foi colocada sobre um apoio que permitiu que o equipamento ficasse sobre um recipiente com água. Então é possível calcular a massa específica da brita 01.

Já para a areia média outro método é utilizado: o procedimento tubo de Chapman com base na norma NBR NM 52:2009. Primeiro, coloca-se uma amostra de areia na estufa $500 \mathrm{~g}$ da areia lavada a estufa para colocá-la no tubo de Chapman que é preenchido com $500 \mathrm{ml}$ de água. O recipiente é agitado levemente para retirar eventuais bolhas de ar. Posteriormente, o aparelho fica em repouso pelo período de 24 horas. Então é realizada a leitura da altura da coluna d'água no tubo e então é aferida a massa específica da areia.

\section{Determinação do traço de concreto}

A determinação do traço de referência é de extrema importância para o desenvolvimento do estudo proposto. $\mathrm{O}$ traço é previamente calculado de acordo com as características dos materiais que são utilizados para obter o concreto com a resistência desejada. Dessa forma, cada componente do concreto é estudo para determinar a sua dosagem na composição final do concreto.

Para a definição do traço foi utilizado o método da Associação Brasileira de Cimento Portland ( $A B C P$ ) com base no trabalho de Rodrigues (1998) e na NBR 12655:2015. Com os estudos e dados obtidos com a 
caracterização dos materiais foi possível o cálculo do traço. Primeiramente, é necessário definir a resistência desejada, e de acordo com a mesma com os cálculos apresentados por Rodrigues (1998), como à principio, o fator água cimento. Para encontrar o fator água cimento é necessário utilizar a curva de Abrams de acordo com fcd e o tipo de cimento. A curva de Abrams é apresentada na Figura 4.

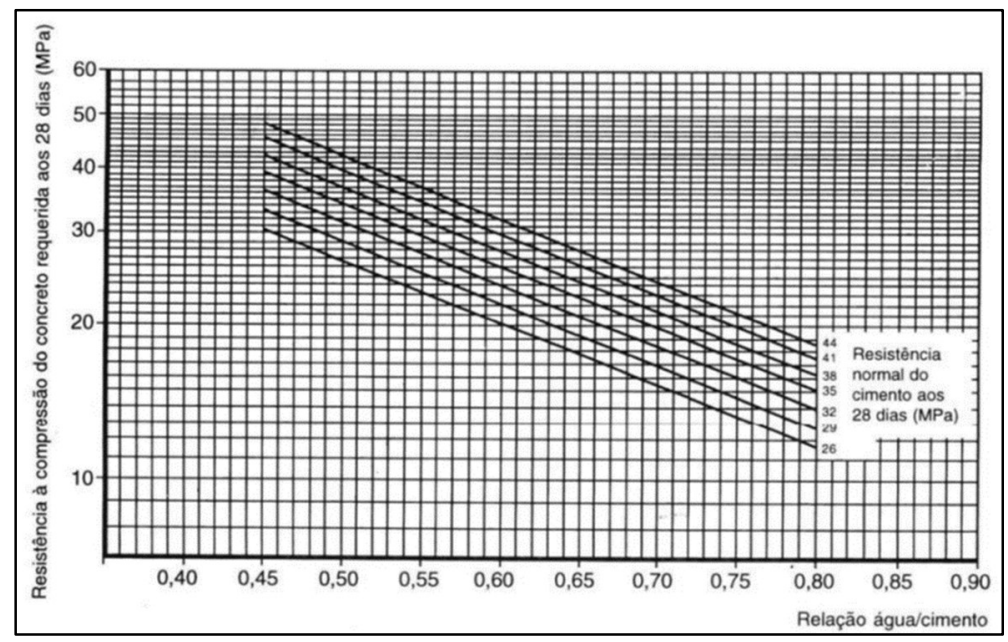

Figura 1: Curva de Abrams.

Após obter o fator água cimento é preciso determinar o consumo dos materiais que fazem parte da composição do concreto. Esse processo foi realizado seguindo as orientações de Rodrigues (1998). Neste momento são utilizados os dados obtidos com os estudos de caracterização dos materiais do concreto feitos anteriormente. Então é definido o traço.

\section{Confecção dos corpos de prova}

O traço definido foi utilizado para a confecção dos corpos de prova de concreto necessários para os ensaios de acordo com a NBR 5738:2016. Dessa forma, definiu-se que seriam feitos 36 corpos cilíndricos de prova ( $\mathrm{Cp}$ 's) de concreto de dimensões $10 \times 20 \mathrm{~cm}$, sendo selecionados $9 \mathrm{Cp}$ 's para cada um dos traços e , dentre esses 9, são utilizados 3 para cada data.

O principal ensaio a ser executado é o de resistência à compressão. Para esse ensaio são determinadas 3 datas para rompimento do $\mathrm{Cp}^{\prime} \mathrm{s}$ de acordo com suas idades, que foram estabelecidas nas idades de 3,7 e 28 dias. Entre os 9 Cp's para cada traço foram divididos 3 para cada data de rompimento. Dessa forma os procedimentos foram realizados com base na NBR 5738:2016.

\section{Adensamento}

De acordo com o resultado do abatimento é definido o método de adensamento. Tal procedimento é realizado de acordo com as instruções da NBR 5738:2016. A mesma norma indica o tipo de adensamento a ser realizado de acordo com a medida em milímetros do abatimento do concreto. Os resultados aferidos neste trabalho foram maiores que $160 \mathrm{~mm}$ de abatimento, sendo assim, de acordo com a norma o método a ser utilizado é o adensamento manual.

$\mathrm{O}$ adensamento manual, com base na mesma norma foi realizado da seguinte maneira: o concreto 
foi colocado no molde separado em duas camadas. Cada camada, ao ser colocada no molde recebeu 12 golpes com a haste de adensamento. Dessa forma foi possível realizar a etapa de adensamento que possui a função de evitar a formação eventuais bolhas de ar e também fazer com que o concreto preencha todo o espaço da fôrma, neste caso, do molde (CARVALHO, 2017).

\section{Cura}

Após os procedimentos citados, os corpos de prova já introduzidos nos moldes, é então iniciado o processo de cura do concreto. Os moldes são colocados em um local adequado. Os Cp's são retirados dos moldes somente 24 horas após o processo de moldagem. Na Figura 2 temos a moldagem dos corpos de prova.

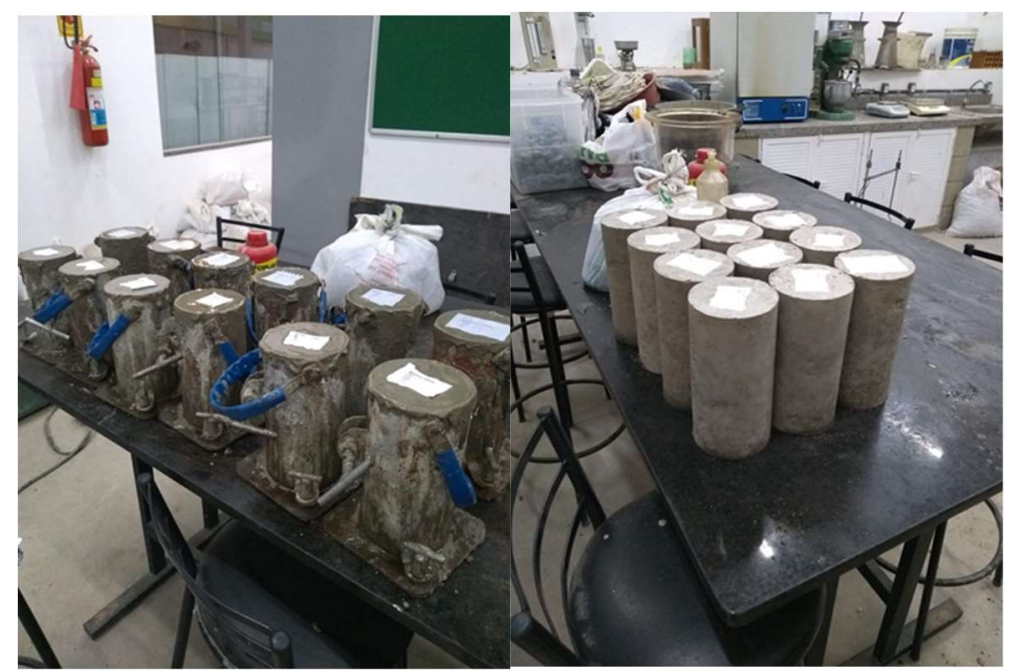

Figura 2: Corpos de Prova.

Após os Cp's serem retirados dos moldes, foram então imersos em um reservatório com água para dar continuidade ao processo de cura. Vale lembrar que antes do processo de cura os $\mathrm{Cp}^{\prime} \mathrm{s}$ foram devidamente identificados com suas respectivas datas de moldagem, traço, número e data de rompimento. Os Cp's permanecem imersos no reservatório até a sua data de rompimento no laboratório de engenharia da UNDB - Unidade de Ensino Superior Dom Bosco. Na Figura 3 é possível obervar os corpos de provas imersos em um reservatório.

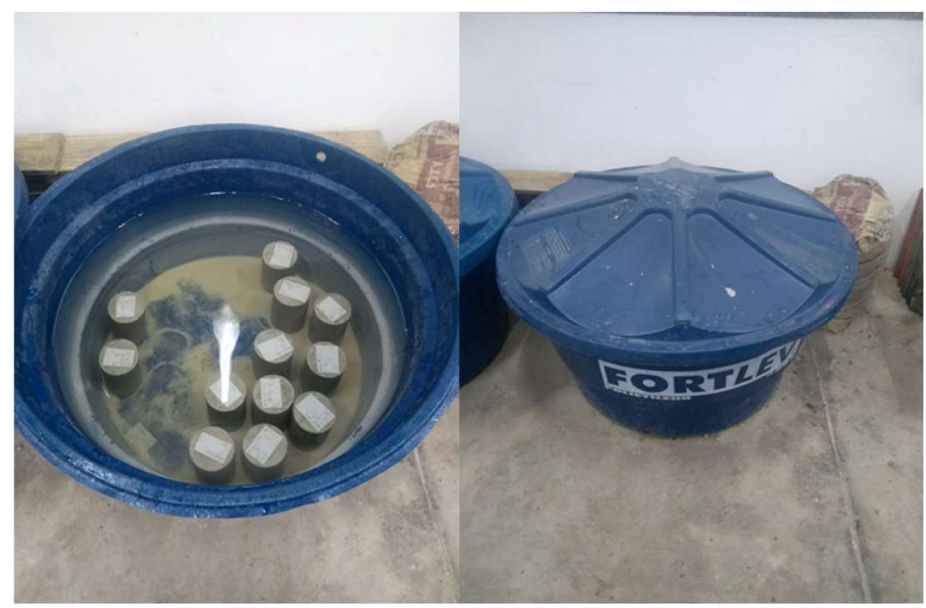

Figura 3: Cp's no reservatório. 


\section{Ensaio de Compressão}

O ensaio de rompimento de corpo de prova é realizado para obter o resultado da resistência do concreto à compressão. Essa se trata de uma das principais características do concreto. A UNDB - Unidade de Ensino Superior Dom Bosco em seu laboratório de engenharia possui a máquina que realiza esse ensaio. Os procedimentos realizados nesse ensaio tem base na norma NBR 5739:2018. Dessa forma, nas datas selecionadas os Cp's foram retirados do reservatório e rompidos por compressão por meio da máquina e coletados os dados sobre as suas respectivas resistências.

\section{RESULTADOS E DISCUSSÃO}

A seguir serão abordados os resultados dos ensaios realizados para avaliar a trabalhabilidade do concreto, bem com sua resistência a compressão. Esses procedimentos são executados com o fim de avaliar as características e o comportamento do concreto com adição de resíduo do corte do mármore e granito em relação ao concreto convencional e verificar as suas eventuais vantagens e desvantagens.

Portanto essa avaliação é feita para analisar a viabilidade e qualidade do concreto com adição. Portanto, são apresentados os resultados:

\section{Trabalhabilidade}

O ensaio de abatimento de tronco de cone é realizado para avaliar a trabalhabilidade do concreto. Esse aspecto está diretamente ligado à facilidade de aplicar o concreto no local desejado, bem como a sua tendência em ser espalhado. O concreto convencional apresentou o resultado de slump de $120 \mathrm{~mm}$. Tal medida significa que o concreto possui uma considerável fluidez. Como possui um aspecto fluído, isso caracteriza uma trabalhabilidade conveniente. Na Figura 4 e 5 temos o slump test do concreto convencional e o slump test do concreto com adição, respectivamente:

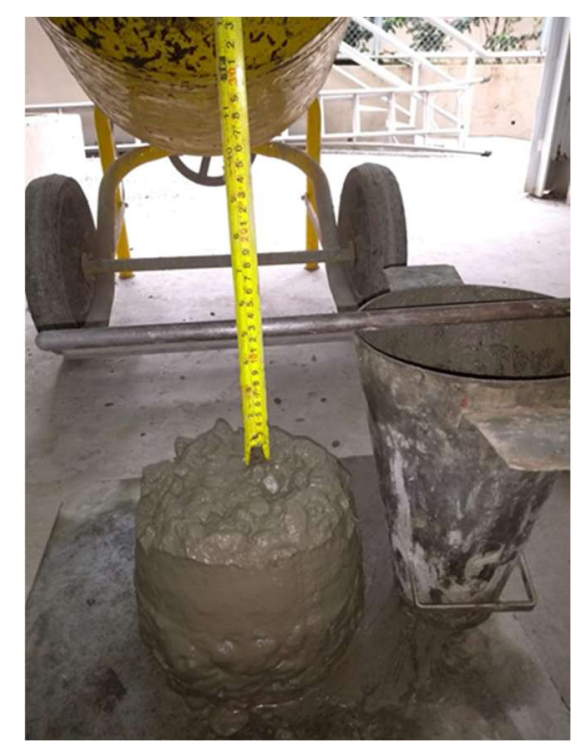

Figura 4: Slump test concreto convencional.

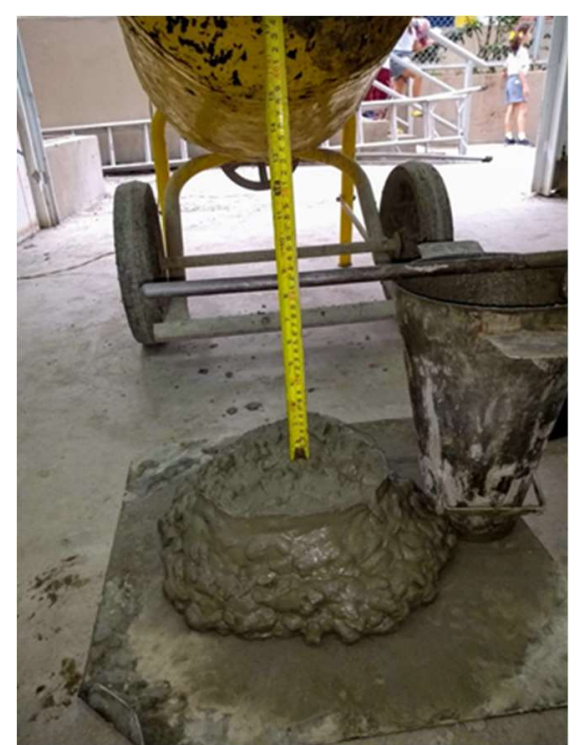

Figura 5: Slump Test concreto com adição.

O concreto com adição do resíduo do corte do mármore e granito apresentou o slump mais alto em 
relação ao convencional: $210 \mathrm{~mm}$, ou seja, um as aspecto bem mais fluído. Isso se deve ao fato do resíduo do corte do mármore e do granito atuar como fíler, um material de granulometria fina que gera aumento na trabalhabilidade. Em função desse fator o concreto apresentou o aspecto mais fluído. No entanto, vale lembrar que é necessária cautela, pois é possível que concretos com slump muito alto possam não ter uma considerável coesão, e por consequência, seja necessário um aumento na quantidade de aglomerante, no caso cimento.

\section{Resistência à Compressão}

Foram ao todo 36 corpos de prova rompidos, 9 para cada traço, dentre esses 9 são 3 para cada data. Desse modo, foi feita média aritmética dos resultados com o mesmo traço e a mesma idade para que fossem encontrados valores mais precisos. Os rompimentos foram executados com o equipamento apropriado para tal ensaio no laboratório de engenharia da UNDB - Unidade de Ensino Dom Bosco. Vale lembrar que cada corpo de prova é previamente pesado e o valor é registrado pela máquina anteriormente a cada rompimento.

Tabela 1: Resistência a compressão dos corpos de prova.

\begin{tabular}{|c|c|c|c|c|c|c|c|}
\hline \multicolumn{8}{|c|}{ Resistência à Compressão (MPa) } \\
\hline \multirow[t]{3}{*}{$\%$} & \multirow[t]{3}{*}{ № $\mathbf{C p}$} & \multicolumn{6}{|c|}{ Resistência (Mpa) } \\
\hline & & \multicolumn{2}{|c|}{3 Dias } & \multicolumn{2}{|l|}{7 Dias } & \multicolumn{2}{|c|}{28 Dias } \\
\hline & & Mpa & Média & Mpa & Média & Mpa & Média \\
\hline \multirow[t]{3}{*}{$0 \%$} & 1 & 15,57 & \multirow[t]{3}{*}{14,87} & 3,667 & \multirow[t]{3}{*}{19,80} & 23,77 & \multirow[t]{3}{*}{26,12} \\
\hline & 2 & 13,86 & & 3,692 & & 26,50 & \\
\hline & 3 & 15,16 & & 3,694 & & 28,07 & \\
\hline \multirow[t]{3}{*}{$5 \%$} & 1 & 19,73 & \multirow[t]{3}{*}{19,29} & 26,03 & \multirow[t]{3}{*}{26,28} & 34,57 & \multirow[t]{3}{*}{33,26} \\
\hline & 2 & 18,89 & & 24,45 & & 31,00 & \\
\hline & 3 & 19,24 & & 28,33 & & 34,19 & \\
\hline \multirow[t]{3}{*}{$10 \%$} & 1 & 16,69 & \multirow[t]{3}{*}{15,94} & 18,19 & \multirow[t]{3}{*}{21,42} & 25,59 & \multirow[t]{3}{*}{25,45} \\
\hline & 2 & 14,31 & & 21,66 & & 24,96 & \\
\hline & 3 & 16.79 & & 24,41 & & 25,80 & \\
\hline \multirow[t]{3}{*}{$15 \%$} & 1 & 13,47 & \multirow[t]{3}{*}{12,60} & 17,23 & \multirow[t]{3}{*}{16,14} & 20,43 & \multirow[t]{3}{*}{22,11} \\
\hline & 2 & 11,32 & & 16,48 & & 21,00 & \\
\hline & 3 & 12,99 & & 14,68 & & 24,86 & \\
\hline
\end{tabular}

Legenda: Dados dos ensaios no intervalo de tempo em 3,7,28 dias.

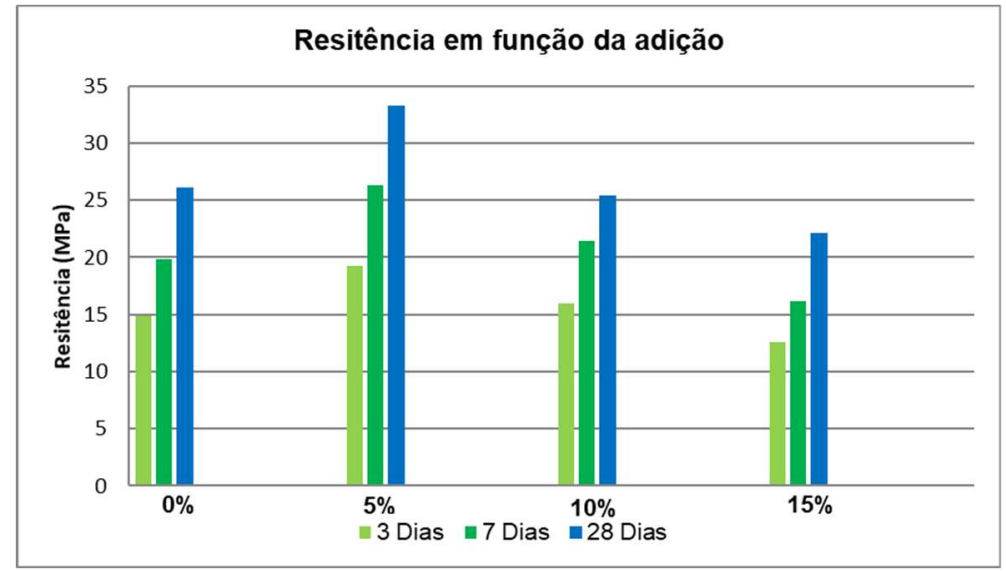

Gráfico 1: Resistência em função da adição.

Então são colocadas duas placas com neoprene sobre o Cp, uma na base e outra no topo. Em seguida o mesmo é introduzido na máquina e é aplicada a carga de compressão sobre o $\mathrm{Cp}$ até o rompimento do mesmo. O equipamento registra o rompimento e apresenta em seu visor digital o resultado da resistência 
máxima atingida em MPa. Em relação aos pesos dos corpos de prova não houve uma grande variação: os pesos foram entre 3,65 Kg a 3,75 Kg. Na Tabela 1 descreve os dados de ressitência á compressão. No Gráfico 1 podemos observar como os valores de resitência em função da adição se comporta nos intervalos de 3, 7 e 28 dias.

A partir do Gráfico, pode-se observar a variação da resistência em função da porcentagem de adição. O concreto convencional atingiu a resistência de $26 \mathrm{MPa}$, um pouco acima do projetado. O traço com $5 \%$ de adição teve um considerável aumento de resistência em comparação ao concreto de referência. Isso se deve ao fato do resíduo do corte do mármore e granito atuar como fíler, que diminui a permeabilidade do concreto, contribui para o preenchimento do composto o que ocasionou em um significativo ganho de resistência à compressão.

Todavia, após a porcentagem de 5\%, na medida em que a proporção de adição cresce, a resistência começa a diminuir. Vale lembrar que por aumentar a quantidade de finos, o composto necessita de maior quantidade de água. Como é possível observar no gráfico, o concreto com 10\% apresentou uma mínima diferença de 2,56\% na resistência aos 28 dias em relação ao concreto convencional. Já o traço com adição de 15\% não atingiu a resistência de $25 \mathrm{MPa}$, que era a resistência prevista para o concreto convencional.

\section{CONCLUSÕES}

Este trabalho buscou apresentar e avaliar o comportamento e as características do concreto com adição de resíduo do corte do mármore e granito em relação ao concreto convencional. Sendo assim foram efetuados os ensaios para obter os dados necessários para tal e foi possível observa-os e analisa-los para chegar ao ponto de conclusão. Dessa forma foi possível obter os seguintes desfechos:

Quanto à trabalhabilidade, a adição do material colabora para o aumento da mesma, o que pode facilitar a aplicação do concreto em determinadas situações onde é necessária uma mistura com grande valor de abatimento. No entanto, é necessária cautela, pois com o aumento da proporção da adição o concreto apresentou uma perda da consistência, o que foi visto na mistura com $15 \%$ de adição.

Em relação à resistência mecânica o material se mostrou satisfatório, além do que apresentou, em determinada proporção, um significativo aumento da resistência na mistura com $5 \%$ de adição, tanto quanto a resistência final como a inicial. Já as outras porcentagens, por mais que não apresentaram ganho da resistência, mas não demonstraram uma grande perda. Vale ressaltar que a dosagem com $5 \%$ de adição apresentou resultados bastante satisfatórios no que diz a respeito à trabalhabilidade como também a resistência, sendo o traço com adição com maiores aspectos positivos.

Dessa forma, é visto que o resíduo do corte do mármore e granito pode ser reutilizado na construção civil em determinadas situações. Tal ação contribui para diminuir a quantidade de resíduos que são despejados no meio ambiente sem qualquer tipo de controle ou cuidado. Portanto, a partir dos resultados e conclusões abordadas, este trabalho pode ser utilizado para auxílio em futuros estudos relacionado à adição do resíduo do corte do mármore e granito ao concreto. 


\section{REFERÊNCIAS}

ABCP. Associação Brasileira de Cimento Portland. Guia básico de utilização do cimento portland. 7 ed. São Paulo: ABCP, 2002

ABNT. Associação Brasileira de Normas Técnicas. NBR NM 45: Agregados: determinação da massa unitária e do volume de vazios. Rio de Janeiro: ABNT, 2006.

ABNT. Associação Brasileira de Normas Técnicas. NBR NM 52: Agregados múdo: Determinação da massa específica e massa específica aparente. Rio de Janeiro: ABNT, 2009.

ABNT. Associação Brasileira de Normas Técnicas. NBR NM 53: Agregados graúdo: Determinação da massa específica e massa específica aparente e absorção de água. Rio de Janeiro: ABNT, 2009.

ABNT. Associação Brasileira de Normas Técnicas. NM 67: Concreto: determinação da consistência pelo abatimento do tronco de cone. Rio de Janeiro: ABNT, 1998.

ABNT. Associação Brasileira de Normas Técnicas. NBR NM 248: Agregados: determinação da composição granulométrica. Rio de Janeiro: ABNT, 2003.

ABNT. Associação Brasileira de Normas Téncicas. NBR 5738: Versão Corrigida Concreto: Procedimento para moldagem e cura de corpos de prova. Rio de Janeiro: ABNT, 2016.

ABNT. Associação Brasileira de Normas Técnicas. NBR 5739: Concreto: Ensaios de compressão de corpos de prova cilíndricos. Rio de Janeiro: ABNT, 2018.

ABNT. Associação Brasileira de Normas Técnicas. NBR 12655: Versão Corrigida Concreto de cimento Portland: Preparo, controle, recebimento e aceitação: Procedimento. Rio de Janeiro: ABNT, 2015.

ALENCAR, C. R. A.. Manual de caracterização, aplicação, uso e manutenção das principais rochas comerciais no Espírito Santo: rochas ornamentais. Cahoeira de Itapemirim: Instituto Euvaldo Lodi, 2013.

BARROS, P. G. S.. Avaliação das propriedades de durabilidade do concreto auto-adensável obtido com resíduo de corte de mármore e granito. Dissertação (Mestrado) - Universidade Federal de Alagoas, Macéio, 2008.

BAUER, L. A. F.. Materiais de construção 1.5 ed. Rio de Janeiro: LTC, 2008

CARVALHO, R. C.; RODRIGUES FILHO, J.. Cálculo e detalhamento de estruturas usuais de concreto armado: segundo a NBR 6118: 2014-4. São Paulo: EdUFSCar, 2017.

FUSCO, P. B.. Tecnologia do concreto estrutural: tópicos aplicados. 2 ed. São Paulo: Pini, 2012.

GARCIA, A.; SPIN, J. A.; SANTOS, C. A.. Ensaios dos materiais. 2 ed. Rio de Janeiro: LTC, 2014.

GONÇALVES, J. P.. Utilização do resíduo de corte de granito (RCG) como adição para produção de concretos.

Dissertação (Mestrado em Engenharia Civil) - Universidade Federal do Rio Grande do Sul, Porto Alegre, 2000.

OLIVEIRA, D. M.; OLIVEIRA, T. N.. Utilização de resíduo de granito como substituição ao cimento Portland em matrizes cimentícias. In: CONGRESSO BRASILEIRO DO CONCRETO, 53. Anais. 2011.

PEDROSO, D. E.; PEDROSO, C. L.. Concretos utilizando resíduo de corte de mármore e granito (RCMG) como substituição parcial do cimento Portland. In: CONGRESSO BRASILEIRO DE ENGENHARIA DE PRODUÇÃO, 7. Anais. Ponta Grossa, 2017.

PEREIRA, L. S.. Influência do uso dos resíduos de corte de granito como fíler no desempenho do concreto. Monografia (Graduação) - Universidade Tecnológica Federal do Paraná, Pato Branco, 2016.

PINHEIRO, A. C. F. B.; CRIVELARO, M.. Materiais de construção. 2 ed. São Paulo: Érica, 2016.

RODRIGUES, P. P. F.. Parâmetros de dosagem do concreto. 3 ed. São Paulo: IBRACON, 1998.

A CBPC - Companhia Brasileira de Produção Científica (CNPJ: 11.221.422/0001-03) detém os direitos materiais desta publicação. Os direitos referem-se à publicação do trabalho em qualquer parte do mundo, incluindo os direitos às renovações, expansões e disseminações da contribuição, bem como outros direitos subsidiários. Todos os trabalhos publicados eletronicamente poderão posteriormente ser publicados em coletâneas impressas sob coordenação da Sustenere Publishing, da Companhia Brasileira de Produção Científica e seus parceiros autorizados. Os (as) autores (as) preservam os direitos autorais, mas não têm permissão para a publicação da contribuição em outro meio, impresso ou digital, em português ou em tradução. 